\title{
Nanoscale
}

Check for updates

Cite this: Nanoscale, 2019, 11, 2109

\section{Blue perovskite light-emitting diodes: progress, challenges and future directions}

\author{
Naresh Kumar Kumawat, ${ }^{a}$ Xiao-Ke Liu, (iD *a Dinesh Kabra (iD) ${ }^{\text {b }}$ and Feng Gao (iD *a
}

Metal halide perovskites have excellent optical and electrical properties and can be easily processed via low-cost solution-based techniques like blade-coating and inkjet printing, promising a bright future for various optoelectronic applications. Recently, encouraging progress has been made in perovskite lightemitting diodes (PeLEDs). Green, red, and near-infrared PeLEDs have achieved high external quantum efficiencies of more than $20 \%$. However, as historically blue electroluminescence remains challenging in all previous LED technologies, we are witnessing a similar case with the development of blue PeLEDs, an essential part of displays and solid-state lighting, which lag far behind those of their counterparts. Herein, we review the recent progress of blue PeLEDs and discuss the main challenges including colour instability, poor photoluminescence efficiency and emission quenching by interlayers. Future directions are provided to facilitate the development of efficient blue PeLEDs.

Received 6th December 2018,

Accepted 2nd January 2019

DOI: $10.1039 / c 8 n r 09885 a$

rsc.li/nanoscale

\section{Introduction}

Metal halide perovskites with a chemical formula of $\mathrm{ABX}_{3}\left(\mathrm{~A}^{+}=\right.$ a monovalent organic or inorganic cation, e.g., $\mathrm{CH}_{3} \mathrm{NH}_{3}{ }^{+}$

${ }^{a}$ Department of Physics, Chemistry and Biology (IFM), Linköping University, Linköping 58183, Sweden.E-mail:xiaoke.liu@liu.se,feng.gao@liu.se

${ }^{b}$ Department of Physics, Indian Institute of Technology Bombay, Powai, Mumbai 400076, India

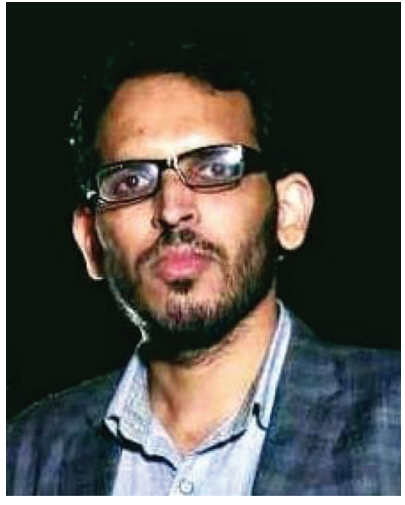

Naresh Kumar Kumawat
Dr Naresh Kumar Kumawat is a postdoctoral fellow with Prof. Feng Gao at the Department of Physics, Chemistry and Biology, Linköping University (LiU). Prior to joining $\mathrm{LiU}$, he received his Ph.D. from the Indian Institute of Technology Bombay (IITB), India in 2018, on organic-inorganic perovskite light-emitting diodes. His research interests are to develop perovskite materials, fabricate perovskite light-emitting diodes, and understand the mechanism of stability.
$\left(\mathrm{MA}^{+}\right), \mathrm{CH}\left(\mathrm{NH}_{2}\right)_{2}{ }^{+}\left(\mathrm{FA}^{+}\right), \mathrm{Cs}^{+} ; \mathrm{B}^{2+}=$ a divalent metal cation such as $\mathrm{Pb}^{2+}$ and $\mathrm{Sn}^{2+} ; \mathrm{X}^{-}=$a halide anion, e.g., $\mathrm{Cl}^{-}, \mathrm{Br}^{-}$, and $\mathrm{I}^{-}$) show excellent optoelectronic properties such as a narrow emission linewidth, high absorption coefficient, readily tunable emission wavelengths covering from ultra-violet to near infrared, wide colour gamut, and high charge carrier mobility. ${ }^{1,2}$ In addition, these materials are solution-processable, which can be easily obtained through simple processing from precursor solutions that contain raw materials such as

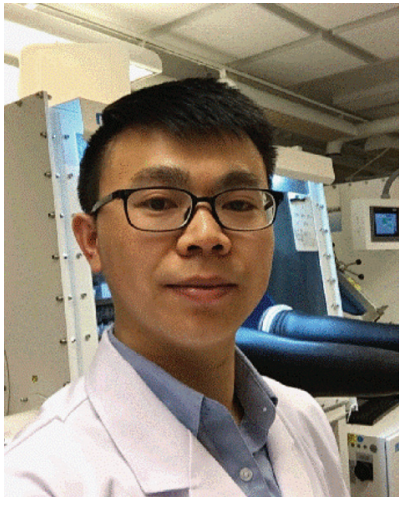

Xiao-Ke Liu
Dr Xiao-Ke Liu is an Assistant Professor at the Department of Physics, Chemistry and Biology at Linköping University. $\mathrm{He}$ received his Ph.D. at the Technical Institute of Physics and Chemistry, Chinese Academy of Sciences in 2014, with focus on organic lightemitting diodes (LEDS). From 2014-2016, he was a Senior Research Associate at COSDAF at the City University of Hong Kong. Later, he moved to Linköping University as a VINNMER and Marie Skłodowska-Curie Fellow. His current research interest is to develop new hybrid organic-perovskite materials for high performance LEDs and solar cells, and to understand the physical origin behind such materials and devices. 
$\mathrm{AX}$ and $\mathrm{BX}_{2}$ salts. These outstanding properties of perovskites make them suitable for a wide range of optoelectronic applications including solar cells, ${ }^{3}$ amplified lasing, ${ }^{4}$ lightemitting diodes (LEDs), ${ }^{5}$ photodetectors, ${ }^{6}$ X-ray detectors, ${ }^{7}$ and so on.

In the past few years, perovskite LEDs (PeLEDs) have shown impulsive progress with external quantum efficiencies (EQEs) boosted from $0.76 \%$ to more than $20 \%$, catching up with other LED technologies such as organic and quantum-dot (QD) LEDs. $^{8,9}$ In 2014, Tan et al. reported the first PeLEDs that show EQEs of $0.76 \%, 0.1 \%$, and $0.018 \%$ for near-infrared, red, and green emission at room temperature, respectively. ${ }^{10}$ Thereafter, tremendous efforts have been devoted to improving the efficiency of PeLEDs through morphology control, ${ }^{11}$ composition engineering, ${ }^{12}$ and device engineering. ${ }^{8,13}$ Very recently, green, red and near-infrared PeLEDs with EQEs of $20.3 \%,{ }^{8} 21.3 \%,{ }^{14}$ and $20.7 \%,{ }^{15}$ respectively, have been reported. These values approach the limits of $\approx 25 \%$ for threedimensional (3D) PeLEDs and $\approx 20 \%$ for quasi-two-dimensional (2D) PeLEDs, which are limited by the out-coupling efficiency. ${ }^{16}$ The encouraging progress promises a bright future for PeLEDs in the applications of displays and solidstate lighting. However, blue PeLEDs, an essential part of displays and lighting, show limited advancement.

In this review, we summarize the recent progress in blue PeLEDs which are categorized into three sections based on the types of perovskite materials, including 3D perovskites, 2D/ quasi-2D perovskites, and colloidal perovskite nanocrystals (PNCs). We discuss the challenges lying in blue PeLEDs and the possible future directions. At present, blue emissive perovskites are mainly achieved by using mixed chloride and bromide, the molar ratio of which can be tuned to adjust the emission colour in the desired blue region. However, mixed-
$\mathrm{Cl} / \mathrm{Br}$ perovskites show electrical-field-induced phase segregation $^{17}$ and reduced photoluminescence quantum efficiency (PLQE). As a result, we will discuss the challenges in terms of colour instability, which is readily observed as a phenomenon of spectral shifts at different voltages or after various time intervals under a constant bias or current, and low PLQE. Plausible strategies are provided to stabilize the colour of blue PeLEDs and improve the PLQEs of blue emissive perovskites. In addition, considering that blue emissive perovskites have wide bandgaps and deep valence band maxima, we will discuss the emission quenching by low-energy interlayers and provide device design strategies for blue PeLEDs. Although we are aware that the operational stability of blue PeLEDs is also significantly important, we do not include it in this review as the operational stability is an open question unsolved for the community of PeLEDs.

\section{Progress in blue PeLEDs}

\subsection{Three-dimensional (3D) perovskites}

Tunable light emission from sky-blue $(490 \mathrm{~nm})$ to deep blue or even ultraviolet $(410 \mathrm{~nm})$ can be realized by increasing the chloride content of mixed-Cl/Br perovskites such as MAPb $\left(\mathrm{Br}_{1-x} \mathrm{Cl}_{x}\right)_{3}$ ( $x$ varies from 0 to 1 ) (Fig. 1a). ${ }^{18}$ The first blue PeLED based on 3D perovskites was reported by Kumawat et al. in 2015 using $\mathrm{MAPbBr}_{1.08} \mathrm{Cl}_{1.92}$, with a poor brightness of $2 \mathrm{~cd} \mathrm{~m}^{-2}$ and an EQE of $0.0001 \%$ at room temperature (Fig. $1 \mathrm{~b}$ and Table 1). ${ }^{18}$ Note that the device efficiency is not optimized, which seems to be limited by pinholes in the film morphology and can provide a shunting path in the device. ${ }^{19}$ Additionally, PCBM ([6,6]-Phenyl $\mathrm{C}_{61}$ butyric acid methyl ester) used as an electron transport layer (ETL) in the device of ITO/PEDOT:PSS/

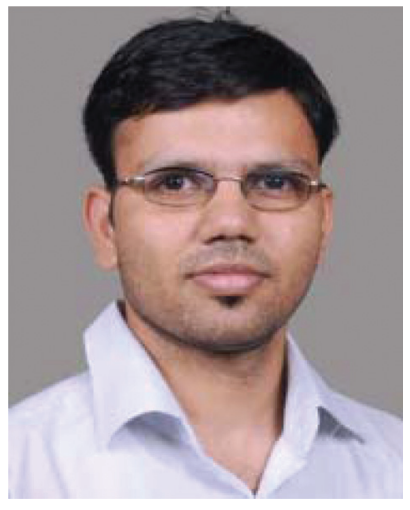

Dinesh Kabra
Dr Dinesh Kabra is an Associate Professor in the Department of Physics at IITB, Mumbai (India). Before joining IITB in 2012, he was a Herchel Smith Research Fellow at the Cavendish Laboratory, University of Cambridge, UK. He is also an honorary postdoctoral fellow of the Trinity Hall College, University of Cambridge. $\mathrm{He}$ received his Ph.D. in 2007 from JNCASR, Bangalore (India) to understand photo-induced charge carrier transport length scales in model conjugated polymer systems. His current research interest involves solution processable inorganic \& organic molecular/metal halide based perovskite semiconductors to understand their charge transport \& photo-physics and transfer that knowledge to design high performance optoelectronic devices.

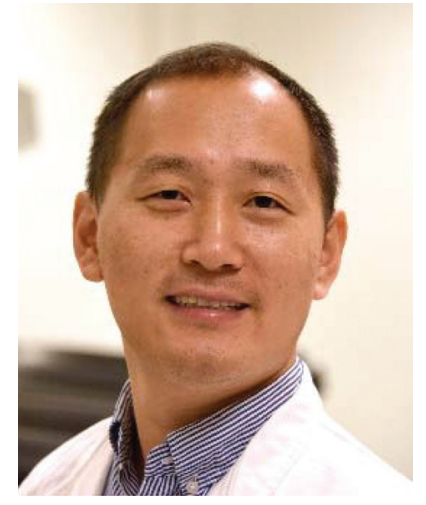

Feng Gao
Dr. Feng Gao is an Associate Professor and Wallenberg Academy Fellow at Linköping University in Sweden. He received his $P h D$ from the University of Cambridge (UK) in 2011, followed by a Marie Curie postdoc fellowship at Linköping University. He received the ERC Starting Grant in 2016. His group currently focuses on the research into solution-processed energy materials and devices, mainly based on organic semiconductors and metal halide perovskites. 

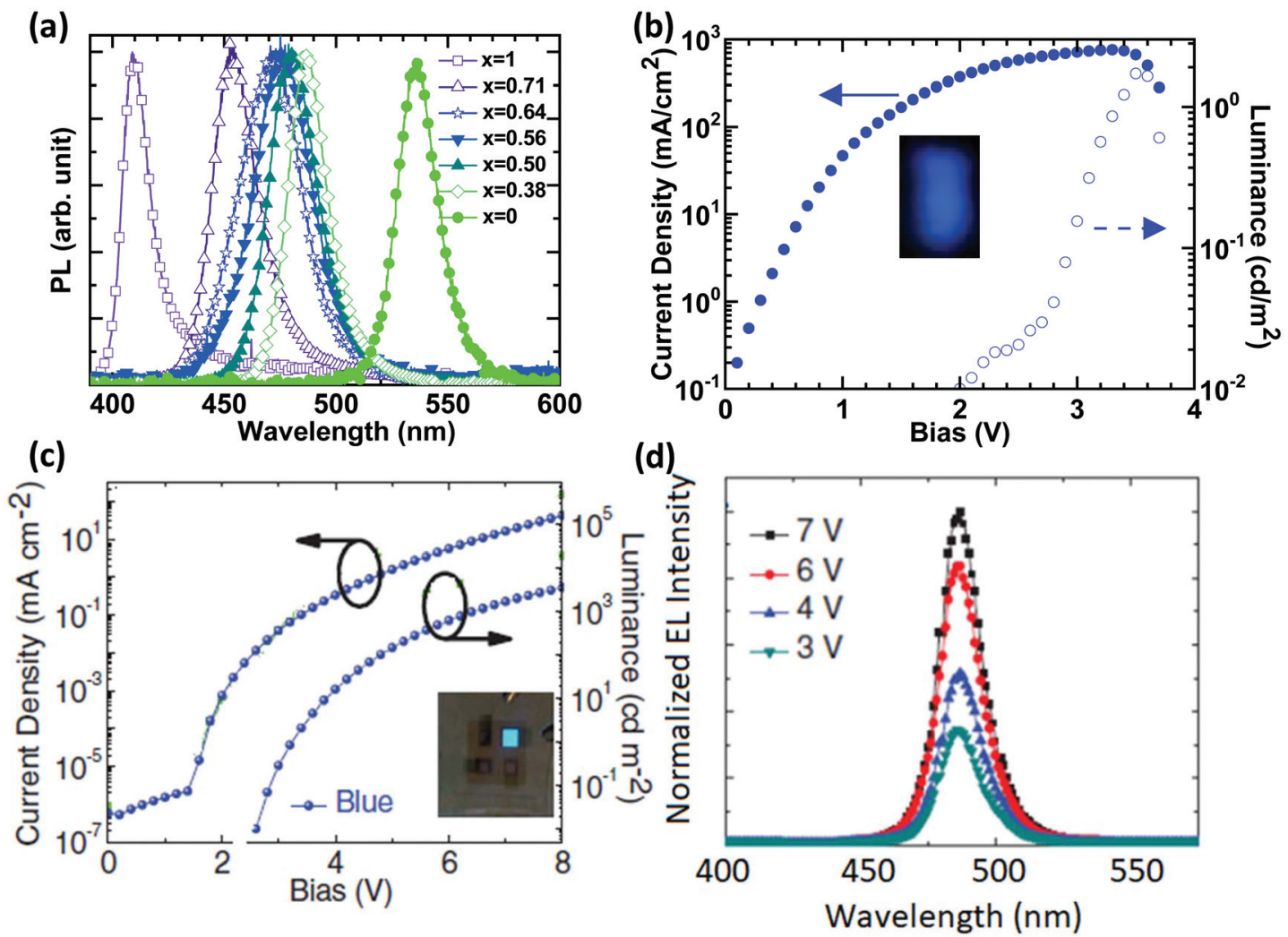

Fig. 1 Bandgap engineering in bulk 3D perovskites and their blue PeLEDs. (a) Tunable blue emissions from $3 D-p e r o v s k i t e s ~ M A P b\left(B r_{1-x} C l_{x}\right)_{3} . J-V-L$ characteristics of (b) $\mathrm{MAPbBr}_{1.08} \mathrm{Cl}_{1.92}$. Reproduced with permission. ${ }^{18}$ Copyright $\odot$ 2015, American Chemical Society and (c) $\mathrm{Cs}_{10}\left(\mathrm{MA}_{0.17} \mathrm{FA}_{0.83}\right)_{100-x} \mathrm{PbBr}_{1.5} \mathrm{Cl}_{1.5}$ based blue devices; the inset images are the photographs of operational blue PeLEDs. (d) Bias dependent EL spectra of the $\mathrm{Cs}_{10}\left(\mathrm{MA}_{0.17} \mathrm{FA}_{0.83}\right)_{100-x} \mathrm{PbBr}_{1.5} \mathrm{Cl}_{1.5}$ based blue device. Reproduced with permission. ${ }^{22}$ Copyright $\odot$ 2017, John Wiley and Sons.

Table 1 Summary of the reported blue PeLEDs

\begin{tabular}{|c|c|c|c|c|c|c|}
\hline Perovskite & Device structure & \multicolumn{4}{|c|}{ Device performance } & Ref. \\
\hline 3D & $\mathrm{ITO} / \mathrm{ZnO} / \mathrm{Cs}_{10}\left(\mathrm{MA}_{0.17} \mathrm{FA}_{0.83}\right)_{100-x} \mathrm{PbBr}_{1.5} \mathrm{Cl}_{1.5} / \alpha-\mathrm{NPD} / \mathrm{MoO}_{3} / \mathrm{Al}$ & 475 & 3564 & $0.138,0.268$ & 1.7 & 22 \\
\hline \multirow[t]{6}{*}{ 2D/Qusai-2D } & ITO/PEDOT:PSS/(PEA) ${ }_{2} \mathrm{PbBr}_{4} / \mathrm{TPBi} / \mathrm{Ca} / \mathrm{Al}$ & 410 & - & - & 0.04 & 25 \\
\hline & $\mathrm{ITO} / \mathrm{ZnO} / \mathrm{PEIE} /(4-\mathrm{PBA})_{2} \mathrm{PbBr}_{4} / \mathrm{TFB} / \mathrm{MoO}_{3} / \mathrm{Al}$ & 491 & 186 & - & 0.015 & 26 \\
\hline & ITO/PEDOT:PSS/( $\left.\mathrm{C}_{4} \mathrm{H}_{9}\right)_{2}(\mathrm{MA})_{n-1} \mathrm{~Pb}_{n} \mathrm{Br}_{3 n+1} / \mathrm{TmPyPB} / \mathrm{LiF} / \mathrm{Al}$ & 450 & 1 & $0.2052,0.1669$ & $5.4 \times 10^{-3}$ & 36 \\
\hline & ITO/PEDOT:PSS/(EA) $)_{2}(\mathrm{MA})_{n-1} \mathrm{~Pb}_{n} \mathrm{Br}_{3 n+1} / \mathrm{TmPyPB} / \mathrm{CsF} / \mathrm{Al}$ & $473(485)$ & 200 & $0.16,0.23$ & 2.6 & 37 \\
\hline & ITO/PEDOT:PSS/IPA:PEA ${ }_{2}$ MA:Cs ${ }_{n-1} \mathrm{~Pb}_{n} \mathrm{Br}_{3 n+1} / \mathrm{TPBi} / \mathrm{LiF} / \mathrm{Al}$ & 490 & 2480 & $0.098,0.174$ & 1.5 & 39 \\
\hline & ITO/PEDOT:PSS/PVK/BA ${ }_{2} \mathrm{Cs}_{n-1} \mathrm{~Pb}_{n}(\mathrm{Br} / \mathrm{Cl})_{3 n+1} / \mathrm{TPBi} / \mathrm{Al}$ & 487 & 3340 & - & 6.2 & 38 \\
\hline \multirow[t]{3}{*}{ PNCs } & ITO/PEDOT:PSS/PVK/CsPb $\left(\mathrm{Br}_{1-x} \mathrm{Cl}_{x}\right)_{3} / \mathrm{TPBi} / \mathrm{LiF} / \mathrm{Al}$ & 455 & 742 & $0.157,0.035$ & 0.07 & 5 \\
\hline & ITO/PEDOT:PSS/PVK/CsPb $\left(\mathrm{Br}_{1-x} \mathrm{Cl}_{x}\right)_{3} / \mathrm{TPBi} / \mathrm{LiF} / \mathrm{Al}$ & 490 & 35 & - & 1.9 & 52 \\
\hline & $\mathrm{ITO} / \mathrm{ZnO} / \mathrm{CsPbBr}_{1.5} \mathrm{Cl}_{1.5} / \mathrm{TFB} / \mathrm{MoO}_{3} / \mathrm{Au}$ & 480 & 8.7 & - & $7 \times 10^{-3}$ & 17 \\
\hline
\end{tabular}

${ }^{a}$ The peak of the EL spectrum including shoulder peak(s) in the brackets. ${ }^{b}$ Maximum luminance. ${ }^{c} \mathrm{CIE}$ coordinates.

$\mathrm{MAPbBr}_{1.08} \mathrm{Cl}_{1.92} / \mathrm{PCBM} / \mathrm{Ag}$ (wherein, ITO is indium-doped tin oxide; PEDOT:PSS is poly(3,4-ethylenedioxythiophene):polystyrene sulfonate) is a strong emission quenching layer which can reduce the device performance. ${ }^{20}$
Attempts were made to improve the EQEs of blue 3D PeLEDs through fabricating pinhole-free perovskite films. Lead acetate was used as a lead source in perovskite solutions with ammonium halides, upon which a blue PeLED was fabricated 
by using the device structure of ITO/Mg:ZnO/MAPb $\left(\mathrm{Br}_{1-x} \mathrm{Cl}_{x}\right)_{3} /$ $\operatorname{CBP}\left(4,4^{\prime}\right.$-bis(9-carbazolyl)-1,1'-biphenyl)/ $\mathrm{MoO}_{3} / \mathrm{Au}$ and demonstrated an EL (electroluminescence) emission peaking at $450 \mathrm{~nm}$ at liquid nitrogen temperature $(77 \mathrm{~K}) .{ }^{21}$ Although lead acetate and molar ratio engineering can help to slow down the crystallization process, pinholes still exist. A triple cation strategy with anti-solvent treatment was reported to achieve a pinhole-free and uniform morphology for blue emission. $^{22}$ A sky-blue PeLED (Fig. 1c), ITO/ZnO/ $\mathrm{Cs}_{10}\left(\mathrm{MA}_{0.17} \mathrm{FA}_{0.83}\right)_{100-x} \mathrm{PbBr}_{1.5} \mathrm{Cl}_{1.5} / \mathrm{NPD}(4,4$-bis$[N$-(1-naphthyl)$\mathrm{N}$-phenylamino]biphenyl)/ $\mathrm{MoO}_{3} / \mathrm{Ag}$, was eventually fabricated and delivered a high brightness of $3567 \mathrm{~cd} \mathrm{~m}^{-2}$ and an EQE of $1.7 \%$ (Fig. 1c and Table 1). ${ }^{22}$ The device also shows remarkably stable EL spectra at different bias voltages (Fig. 1d). This suggests that triple cations can help to prevent phase segregation in mixed halide perovskites. ${ }^{23}$

\subsection{Two-dimensional (2D) and quasi-2D perovskites}

2D perovskites, also called layered or Ruddlesden-Popper perovskites (RPPs) with $n=1$, have a general formula of $\left(\mathrm{RNH}_{3}\right)_{2} \mathrm{BX}_{4}$, where $\mathrm{R}$ is an aryl or alkyl long chain group. ${ }^{24}$ The first blue PeLED based on 2D perovskites was reported by Liang et al. using (PEA) ${ }_{2} \mathrm{PbBr}_{4}$ (here, PEA is phenylethylammonium) as the emissive layer, which demonstrated light emission peaking at $410 \mathrm{~nm}$ at room temperature with an EQE of $0.04 \% .^{25}$ By changing the organic spacer layer, Cheng et al. reported a sky-blue PeLED of ITO/ZnO/PEIE/(4-PBA $)_{2} \mathrm{PbBr}_{4} /$ $\mathrm{TFB} / \mathrm{MoO}_{3} / \mathrm{Al}$ (wherein, PEIE is polyethylenimine ethoxylated, TFB is poly(9,9-dioctyl-fluorene-co- $N$-(4-butylphenyl) diphenyl- amine), and 4-PBA is 4-phenylbutylamine), showing a brightness of $186 \mathrm{~cd} \mathrm{~m}^{-2}$ and an EQE of $0.015 \% .^{26}$ The formation of the quantum confinement effect is a very plausible way to realize blue emission from pure halide perovskites; however, 2D perovskites have limited PLQEs due to strong excitonphonon coupling, which consequently limits the EQEs of blue 2D PeLEDs. ${ }^{27}$

The combination of $2 \mathrm{D}$ and $3 \mathrm{D}$ perovskites, named quasi2D perovskites or RPPs with high $n$ values $(n>1)$, were reported as a useful strategy for promoting the PLQEs. ${ }^{28,29}$ This strategy has been successfully demonstrated in green and infrared PeLEDs with EQEs of more than $10 \% .^{30,31}$ In general, quasi-2D perovskites have a formula of $\left(\mathrm{RNH}_{3}\right)_{2} \mathrm{~A}_{n-1} \mathrm{~B}_{n} \mathrm{X}_{3 n+1}$, where $n$ is the number of stacking perovskite octahedra. The bandgap can be tuned by changing the $n$ values, becoming attractive as blue emitters of pure halides (Fig. 2a). In addition, these materials not only provide good moisture stability and compact pinhole-free morphology, ${ }^{32}$ but also have excellent optoelectronic properties such as high PLQEs and good charge carrier balance. ${ }^{33}$ Kumar et al. prepared quasi-2D perovskites $\mathrm{OLA}_{2} \mathrm{MA}_{n-1} \mathrm{~Pb}_{n} \mathrm{Br}_{3 n+1}$ ( $n=1-7$; OLA = oleylammonium $)$ using low- $k$ dielectric organic materials to increase the exciton binding energy by dielectric confinement. ${ }^{34}$ A blue PeLED with an emission peak at $456 \mathrm{~nm}$ was realized, delivering an EQE of $0.0024 \%$ and a brightness of $2 \mathrm{~cd} \mathrm{~m}^{-2}$. The device performance was further improved by employing a new organic material PEOA (2-phenoxyethylamine), reaching a brightness of $19.5 \mathrm{~cd} \mathrm{~m}^{-2}$ and an EQE of $1.1 \% .^{35}$ A similar approach with an excess amount of ligand was used to obtain blue emission (a)
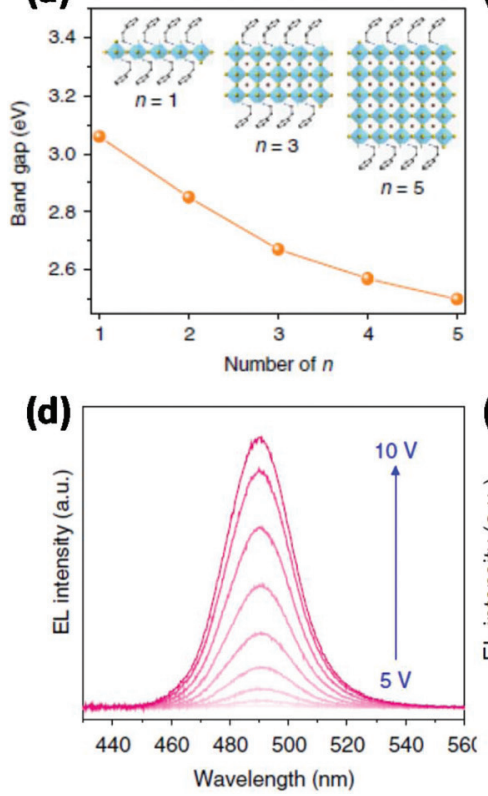

(b)
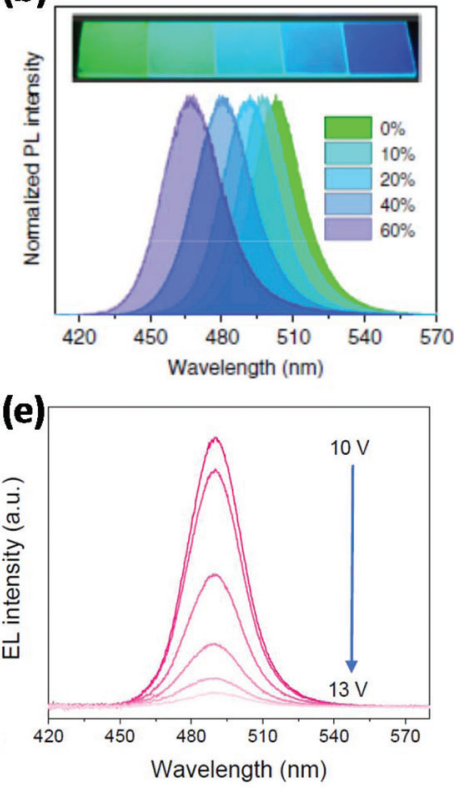

(c)

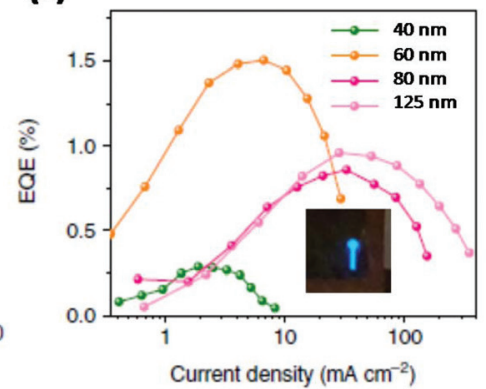

(f)

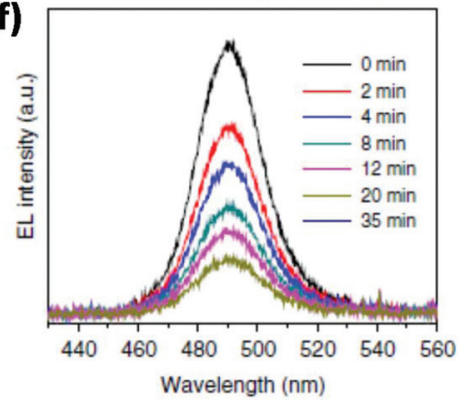

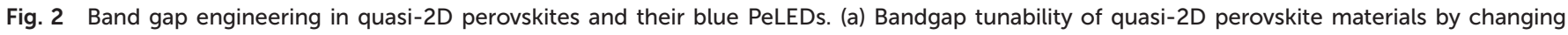

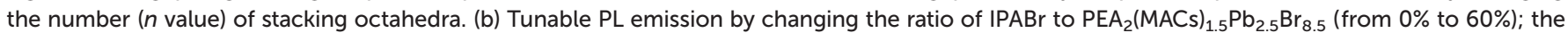

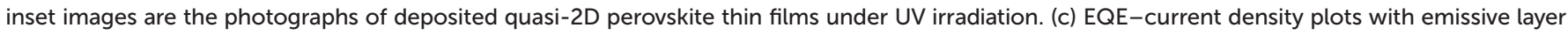

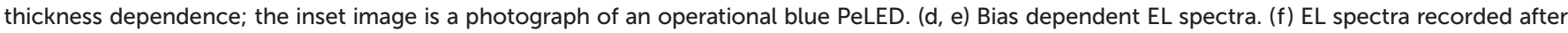
different time intervals. Reproduced with permission. ${ }^{39}$ Copyright $\odot 2018$, Springer Nature. 
and achieved a blue PeLED of ITO/PEDOT:PSS/ $(\mathrm{BA})_{2}(\mathrm{MA})_{n-1} \mathrm{~Pb}_{n} \mathrm{Br}_{3 n+1} / \mathrm{TmPyPB} / \mathrm{LiF} / \mathrm{Al}$ (wherein, BA is $n$-butylammonium; TmPyPB is 1,3,5-tri( $m$-pyridin-3-ylphenyl) benzene) with $0.0054 \%$ EQE. ${ }^{36}$ Wang et al. used ethylammonium bromide (EABr) to fabricate quasi-2D perovskite thin films and realized a brightness of $100 \mathrm{~cd} \mathrm{~m}^{-2}$ and an EQE of $2.6 \%$ for blue emission peaking at $473 \mathrm{~nm} .{ }^{37}$ Very recently, a high-efficiency blue PeLED was achieved based on quasi-2D perovskites, showing an EQE of $6.2 \%$ with an emission peak of $487 \mathrm{~nm} .^{38}$

Although quasi-2D perovskites have a formula with a constant $n$ value, the resulting films prepared following the nominal formula are usually a mixture of RPPs with various $n$ values. ${ }^{34,35}$ As a result, quasi-2D perovskites can show double or triple peaks in EL spectra, which could lead to colour instability under the operation of blue devices. ${ }^{39}$ However, a careful selection of organic spacer materials can stabilize the EL spectra. For instance, Xing et al. used PEABr, IPABr (iso-propylammonium bromide), $\mathrm{PbBr}_{2}, \mathrm{CsBr}$ and $\mathrm{MABr}$ to synthesize quasi-2D perovskites for blue emission (Fig. 2a and b), realizing a blue emissive perovskite with a high PLQE of $88 \%$ the PL spectrum of which peaks at $477 \mathrm{~nm} .{ }^{39}$ Finally, they reported a sky-blue PeLED peaking at $490 \mathrm{~nm}$ with a brightness of $2480 \mathrm{~cd} \mathrm{~m}^{-2}$ and an EQE of $1.5 \%$ (Fig. 2c). In addition, the colour stability was tested by recording the EL spectra at different driving voltages from 5 to $13 \mathrm{~V}$ and after various time intervals. As shown in Fig. $2 \mathrm{~d}-\mathrm{f}$, the shape of the EL spectra remains the same at different driving voltages and under different time intervals, suggesting excellent colour stability of the quasi-2D blue device.

\subsection{Colloidal perovskite nanocrystals (PNCs)}

\subsubsection{Synthesis of PNCs}

Hot-injection method. The hot-injection method is one of the pioneering techniques for synthesizing CdSe nanocrystals. It also has been widely used for synthesizing other nanocrystals including PNCs. Fig. 3a (left panel) shows a schematic diagram of the hot-injection setup. In general, lead halides are dissolved in 1-octadecene (ODE) together with organic ligands (e.g., oleylamine and oleic acid). The solution is then stirred at a certain temperature in nitrogen during which Cs-oleate (Cs-OA) solution is added. ${ }^{1}$ The mixed solution is then cooled down in an ice bath. The precipitates are collected and purified with nonpolar solvents such as toluene and hexane. A colloidal PNC solution can be obtained when the precipitates are dispersed into a nonpolar solvent. Success in synthesizing blue emitting colloidal PNCs using the hot-injection method was achieved by Protesescu and co-workers, when they obtained a series of highly luminescent colloidal $\mathrm{CsPb}\left(\mathrm{Br}_{1-x} \mathrm{Cl}_{x}\right)_{3}(0<x<1)$ PNC solutions with PLQEs up to $90 \%{ }^{1}$ Fig. $3 \mathrm{~b}$ shows the photographs of the colloidal PNC solutions under UV light and their PL spectra, the emission colour of which was tuned by changing the bromide to chloride ratio. In addition, reducing the size of $\mathrm{CsPbBr}_{3}$ PNCs from $11.8 \mathrm{~nm}$ to $3.8 \mathrm{~nm}$ can also tune the emission wavelength from $510 \mathrm{~nm}$ to $450 \mathrm{~nm}$ because of the quantum confinement effect. ${ }^{1}$ Note that the properties of PNCs are sensitive to the reaction temperature and the chain length of the organic ligands, which can control the size of PNCs. ${ }^{40-42}$ But the reaction time has a negligible influence as the formation of PNCs happens within several seconds. ${ }^{43}$

Ligand-assisted reprecipitation (LARP) technique. The LARP method is simple and versatile compared to the hot-injection method. Fig. 3a (right panel) shows the setup for LARP, where the perovskite precursor solution containing organic ligands is added dropwise into a nonpolar solvent. ${ }^{44}$ Immediately, colloidal PNC solution can be obtained. However, continuous addition of the precursor solution will lead to the formation of precipitates, which may not be dispersed into nonpolar solvents.

Although both the hot-injection and LARP methods can generate blue-emitting colloidal PNCs, the organic ligands

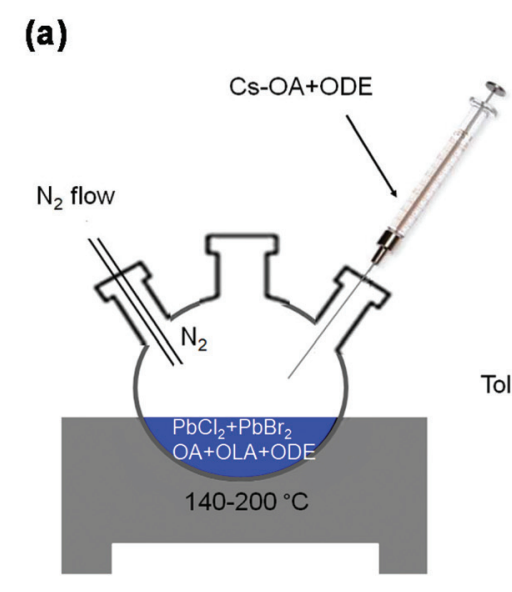

Hot-Injection

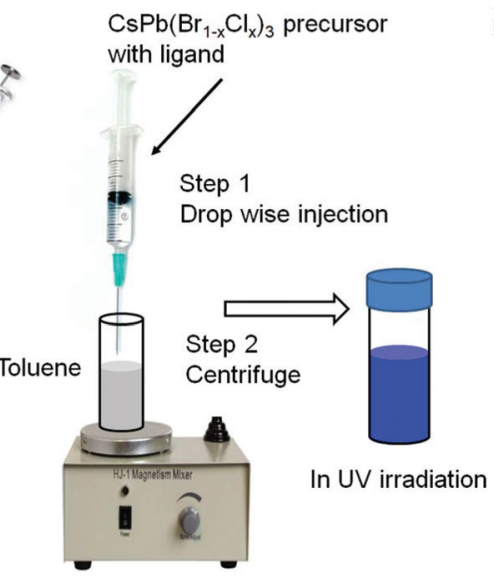

LARP (b)

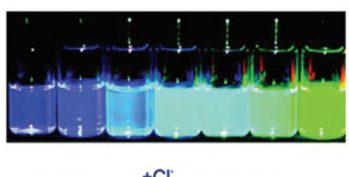

$$
\mathrm{CsPbCl}_{3} \underset{+\mathrm{Br}}{\stackrel{+\mathrm{Cl}}{\rightleftarrows}} \mathrm{CsPbBr}_{3}
$$

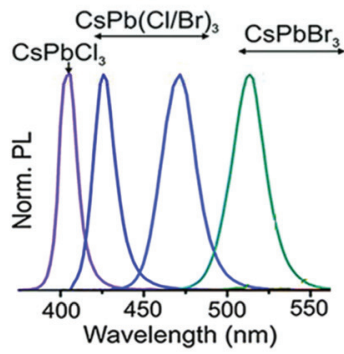

Fig. 3 Synthesis of colloidal PNCs and bandgap tuning via anion-exchange. Schematic diagrams of (a) the hot-injection method (left panel) and the LARP technique (right panel). (b) Photographs of colloidal $\mathrm{CsPb}\left(\mathrm{Br}_{1-x} \mathrm{Cl}_{x}\right)_{3} \mathrm{PNC}$ solutions under UV irradiation and their PL spectra, wherein emission shifts towards the deep blue region with higher chloride/bromide ratios. Reproduced with permission. ${ }^{1}$ Copyright $\odot 2015$ American Chemical Society. 
adhered to PNC surfaces play an important role in their stability and efficiency. ${ }^{45}$ The amount of organic ligands can be adjusted to control the nucleation and growth of PNCs. The shape, size and surface properties of PNCs also depend on the surface ligands other than the processing conditions. ${ }^{40}$ For instance, Sun et al. used oleic acid and oleylamine as capping agents and obtained monodisperse cubic shape PNCs; however, excess oleylamine can change the shape of the PNCs from cubic to nanorods and nanowires. ${ }^{46}$

In addition, PNCs with different shapes can be realized by varying the chain length of the amine and acidic group of the ligands. ${ }^{47}$ Moreover, it was reported that the modification of the organic ligands can change the stability and PLQEs of PNCs. Colloidal PNCs synthesized with oleic acid and oleylamine ligands are not stable in storage because of the dynamic change in the binding with the surface of PNCs. An amine-free strategy was reported to improve the stability of the colloidal solution using oleic acid only. ${ }^{48}$ Bulky ligands with steric hindrance such as POSS (polyhedral oligomeric silsesquioxane), TPTES ((3-aminopropyl)triethoxysilane), and TOPO (tri-octylphosphine oxide), are also conducive to slow down the degradation process and thus improve the stability of PNCs. ${ }^{49-51}$ These ligands can also passivate the surface defects of PNCs and therefore increase their PLQEs up to $55 \% .^{52}$ However, organic ligands, especially those with long alkyl chains, have poor electrical conductivity, which will form carrier injection barriers in LEDs and thus will lead to high driving voltages and poor device performance. ${ }^{5}$ A balance between the stability of the colloidal solution of PNCs and their electrical properties is a crucial gap and requires attention from the perovskite materials synthesis community.

2.3.2 Blue PeLEDs based on colloidal PNCs. The first PNCbased PeLED was reported by Schmidt et al., in which $\mathrm{MAPbBr}_{3} \mathrm{PNCs}_{\mathrm{N}}$ with good stability and high PLQEs were used. ${ }^{2}$ However, the EQE was poor because of the poor morphology of the thin film deposited from the colloidal PNC solution. After that, Xing et al. synthesized $\mathrm{MAPbBr}_{3}$ PNCs using the LARP method and fabricated green LEDs with EQEs up to $3.8 \% .^{53}$ Using a similar approach, Song et al. reported efficient $\mathrm{CsPbBr}_{3}$ PNCs the sub-bandgap states of which were passivated by using $\mathrm{ZnBr}_{2}$ and $\mathrm{FA}$, and realized green LEDs with a high EQE of $16.48 \%{ }^{45}$ Using an anion-exchange approach, Chiba et al. reported $21.3 \%$ EQE for red PNC-based PeLEDs. ${ }^{14}$ However, the development of blue PNC-based PeLEDs lags far behind those of green and red counterparts. ${ }^{8,14,45}$

The first attempt on blue PNC-based PeLEDs was made by Song at al., who synthesized blue $\operatorname{CsPb}\left(\mathrm{Br}_{1-x} \mathrm{Cl}_{x}\right)_{3}(0<x<1)$ PNCs using the hot-injection method, and fabricated a blue PeLED with a turn-on voltage of $5.1 \mathrm{~V}$ (at $1 \mathrm{~cd} \mathrm{~m}^{-2}$ ), an EQE of $0.07 \%$, and a maximum brightness of $742 \mathrm{~cd} \mathrm{~m}^{-2}{ }^{5}$ Fig. $4 \mathrm{a}$ shows a high-resolution transmission electron microscopy (HRTEM) image of blue emissive $\mathrm{CsPbBr}_{1.2} \mathrm{Cl}_{0.8}$ PNCs, which have a cubic shape with an average size of $8 \mathrm{~nm}$. The PL (dotted line) and EL (solid line) spectra of these PNCs are shown in Fig. 4b, a peak of which at about $455 \mathrm{~nm}$ with $20 \mathrm{~nm}$ fwhm (full width at half maxima) can be observed. Fig. 4c demonstrates the device structure; they used poly(9-vinylcarbazole) (PVK) as the hole transport layer (HTL) which can also
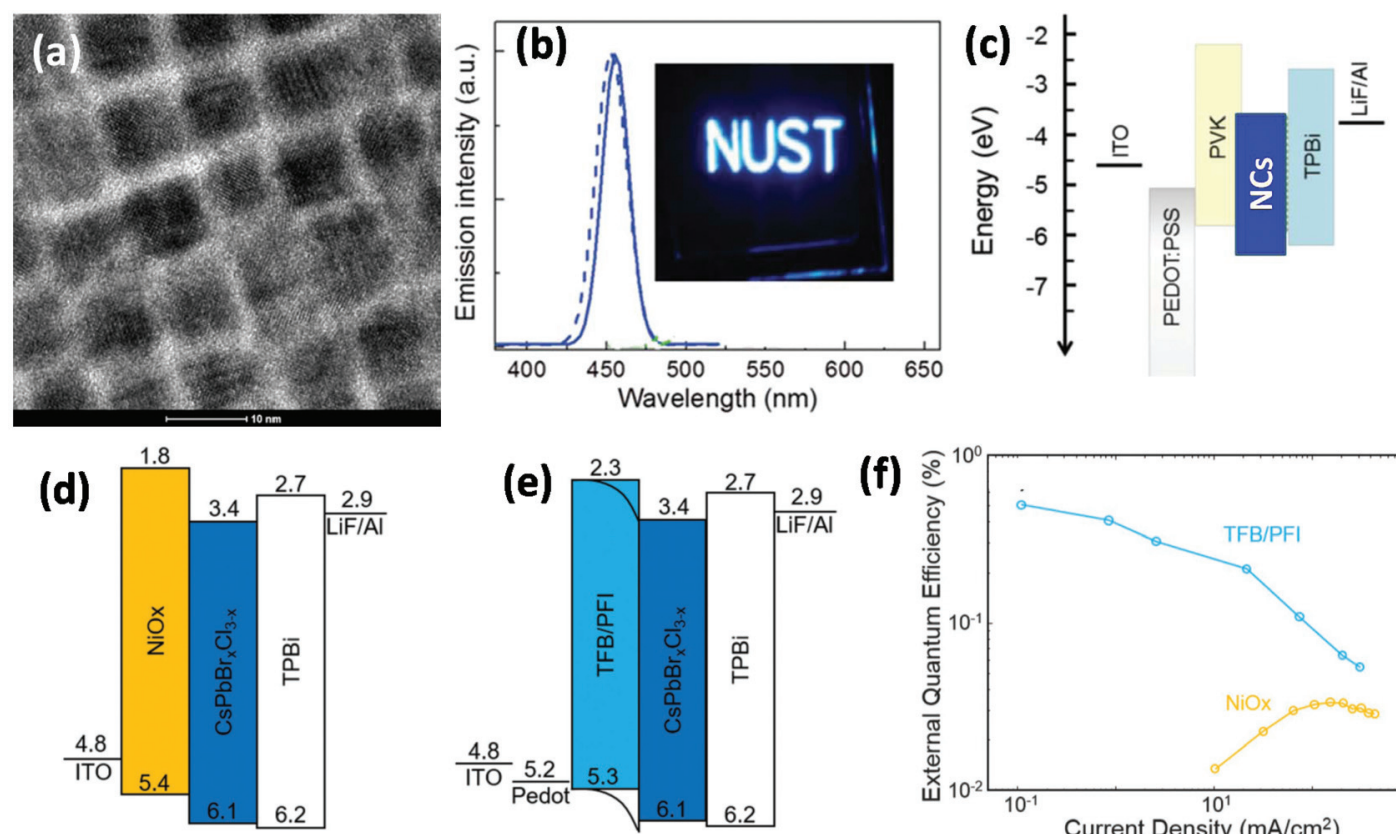

(f)

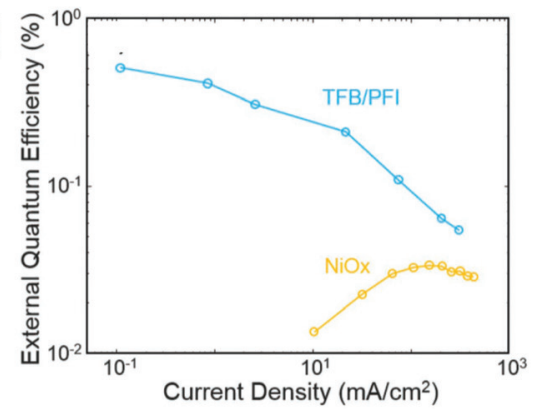

Fig. 4 Blue PNC-based PeLEDs. (a) HRTEM image with a scale bar of $10 \mathrm{~nm}$, and (b) EL (solid line) and PL (dotted line) spectra of $\mathrm{CsPbBr}_{1.2} \mathrm{Cl}_{0.8}$ PNCs; the inset image is the photograph of a blue PNC-based LED under operation. Reproduced with permission. ${ }^{5}$ Copyright $\odot 2015$, John Wiley and Sons. (c-e) Energy level diagrams of blue PeLEDs. (d) EQE-current density plots for $\mathrm{NiO}_{x}$ and TFB/PFI based blue devices. Reproduced with permission. ${ }^{54}$ Copyright @ 2018, John Wiley and Sons. 
prevent the interface emission quenching caused by PEDOT: PSS. Similarly, severe emission quenching was found at the $\mathrm{NiO}_{2} / \mathrm{CsPb}\left(\mathrm{Br}_{1-x} \mathrm{Cl}_{x}\right)_{3}$ interface (Fig. $4 \mathrm{~d}$ ), which can be suppressed by using TFB/PFI (perfluorinated ionomer) (Fig. 4e) instead of $\mathrm{NiO}_{2}{ }^{54}$ Such a modification can improve the EQE from $0.03 \%$ to $0.5 \%$ for deep blue PeLEDs (Fig. $4 \mathrm{f}$ ). ${ }^{54}$

To realize efficient blue PNC-LEDs, the ligand density and surface defects of PNCs also need to be optimized for better charge injection. Pan and co-workers performed surface engineering for ligand density optimization to achieve better charge injection. ${ }^{52}$ This was enabled by treating the synthesized PNCs with oleylamine and oleic acid using DDABC (di-dodecy dimethyl ammonium bromide chloride) via the ligand exchange strategy. Upon this, they achieved a sky-blue PeLED (the device structure is the same as that in Fig. 4c) with a turnon voltage of $3.0 \mathrm{~V}$, an EQE of $1.9 \%$, and a luminance of $35 \mathrm{~cd}$ $\mathrm{m}^{-2}$. The relatively low turn-on voltage suggests that the charge injection is improved after ligand density optimization. However, the ligand exchange process might change the crystallinity and crystal arrangement of PNCs, leading to cracks and defects in their thin films and hence reduce the device performance. ${ }^{17} \mathrm{Li}$ et al. reported a cross-linking method to replace a long chain ligand by a short chain ligand using TMA (trimethylaluminum) treatment. ${ }^{17}$ This method will not affect the PNC arrangement and can lead to stable PNCs. A blue PeLED was thus fabricated using a device structure of ITO/ $\mathrm{ZnO} / \mathrm{CsPb}\left(\mathrm{Br}_{1-x} \mathrm{Cl}_{x}\right)_{3} / \mathrm{TFB} / \mathrm{MoO}_{3} / \mathrm{Au}$, showing an EQE of $0.007 \%$ and a luminance of $8.7 \mathrm{~cd} \mathrm{\textrm {m } ^ { - 2 } \cdot 1 7}$ In addition, they observed an electrical-induced phase segregation effect in their blue device, the EL peak of which shifts towards green emissive Br-rich domains with increasing time intervals at a constant applied voltage. Phase segregation is a common phenomenon in mixed halide perovskites, which takes place at grain boundaries where a higher concentration of positive space charge possibly provides the initial driving force ${ }^{55,56}$ It is a serious stability issue that should be addressed in blue PeLEDs as most of the reported blue emissive perovskites are achieved based on the mixed-Br/Cl strategy. Possible strategies that can improve the colour stability will be discussed later.

In addition to the control of the organic ligands and surface defects, manganese (Mn) doping in PNCs can increase their PLQEs and thus improve the EQE of blue PeLEDs. ${ }^{57}$ Despite the fact that Mn-doped PNCs are reported with an additional emission peak from $\mathrm{Mn}^{2+58}$ a small amount of doping will not influence the emission colour; instead, it can increase the PLQE from $9 \%$ to $28 \%$ (Fig. 5a). ${ }^{57}$ They finally fabricated a bright PeLED with a luminance of $400 \mathrm{~cd} \mathrm{~m}^{-2}$ and an EQE of $2.12 \%$ (Fig. $5 b$ and c). It is also worthwhile to note that Mn-doped devices show narrower EL spectra compared to the control device (Fig. 5d).

\section{Challenges and future directions}

\subsection{Colour stability}

Blue emissive perovskites are prepared from mixed halide $(\mathrm{Br} / \mathrm{Cl})$ ions or low-dimensional NCs with the quantum confinement effect. From the material stability point of view, the
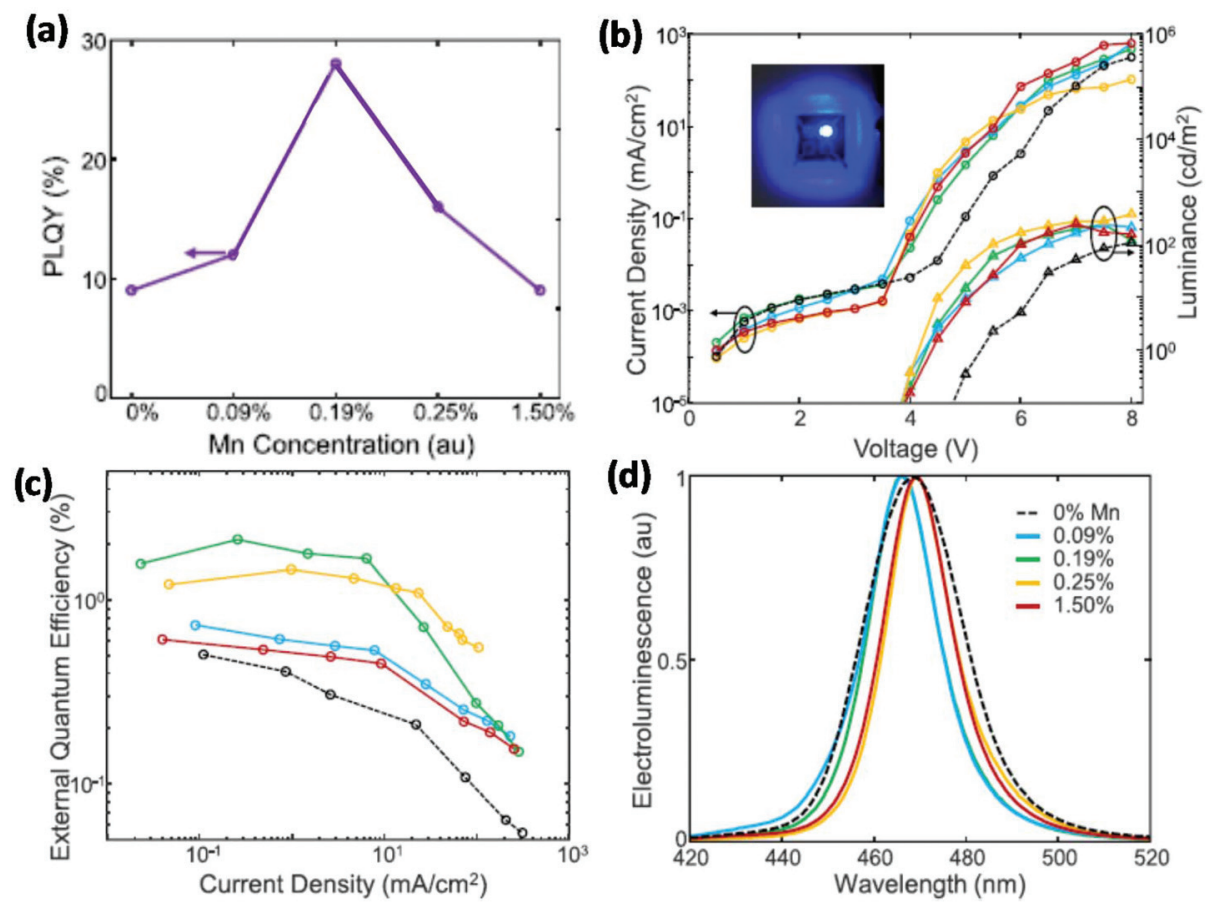

Fig. 5 Blue PeLEDs based on Mn-doped PNCs with various doping concentrations. (a) PLQEs of Mn-doped PNCs. (b) J-V-L characteristics; the inset image is a photograph of a blue LED under operation. (c) EQE-current density plots. (d) EL spectra. Reproduced with permission. ${ }^{57}$ Copyright $\odot 2018$ Elsevier Inc. 
phase segregation and moisture stability of mixed halide perovskites need to be investigated in depth. These materials show reversible electrical-field-induced phase segregation in blue PeLEDs. ${ }^{17}$ As shown in Fig. $6 a$ and b, the blue EL peak shifts towards green (from Cl-rich to Br-rich domains) wavelengths under operation of the device at a constant bias voltage of $5.5 \mathrm{~V}$; after resting for $20 \mathrm{~min}$, the blue PeLED recovered blue emission. Metal stearate (MSt), which works as a capping agent that binds to the surface of PNCs, was successfully reported to prevent potential damage during the PNC purification process. $^{59}$ It was also reported that anion exchange between $\mathrm{CsPbBr}_{3}-\mathrm{MSt}$ and $\mathrm{CsPbI}_{3}-\mathrm{MSt}$ nanocomposites was greatly suppressed. This suggests that the efficient coating of MSt can effectively isolate the contact between $\mathrm{CsPbBr}_{3}$ and $\mathrm{CsPbI}_{3}$ nanocrystals, reflecting notable compositional stability. ${ }^{59}$ As a result, stable $\operatorname{CsPb}\left(\mathrm{I}_{1-x} \mathrm{Br}_{x}\right)_{3}$ PNCs were realized via impregnating them in MSt, which show a good colour stability under ambient conditions (Fig. 6c). Moreover, solvents with high dielectric constants can damage PNCs and create ionic defects during the purification of PNCs. ${ }^{14,60}$ A careful selection of the solvents can lead to stable PNCs. For instance, Chiba et al. used ethyl acetate (AcOEt) to wash long chain ligands such as alkyl-based oleylammonium iodide (OAM-I) and aryl-based aniline hydoroiodide (An-HI) of
$\operatorname{CsPb}\left(\mathrm{I}_{1-x} \mathrm{Br}_{x}\right)_{3}$ PNCs, upon which PeLEDs were fabricated with stable EL spectra peaking at $650 \mathrm{~nm}$ under various current densities (Fig. 6d). ${ }^{14}$ Similar methods can be used to synthesize PNCs for blue PeLEDs with good colour stability.

In addition, Braly et al. replaced the MA cation by FACs cations and demonstrated stable emission from mixed bromide-iodide perovskites. ${ }^{55}$ It was reported that FACs-based mixed halide perovskites will ultimately show similar phase segregating behaviour but they can be more stable than MA-based perovskites. A combination of larger morphological grains and the presence of size mismatch on the perovskite monovalent cation site in FACs-based perovskites stabilize these materials. ${ }^{55}$ Similar approaches can be developed to suppress the electrical-field-induced phase segregation in mixed$\mathrm{Br} / \mathrm{Cl}$ perovskites for colour-stable blue emission. One successful example was reported for triple cation based blue PeLEDs, which show stable EL spectra at different bias voltages (Fig. 1d). ${ }^{22}$ Furthermore, as mentioned above, the careful selection of the organic spacer materials for quasi-2D perovskites can also lead to colour-stable blue PeLEDs (Fig. 2d-f)..$^{38,39}$ Another plausible way is to decrease the dimensionality of pure bromide perovskites that feature the quantum confinement effect to realize blue emission. Such an approach has been successfully applied in pure iodide perovskites that show
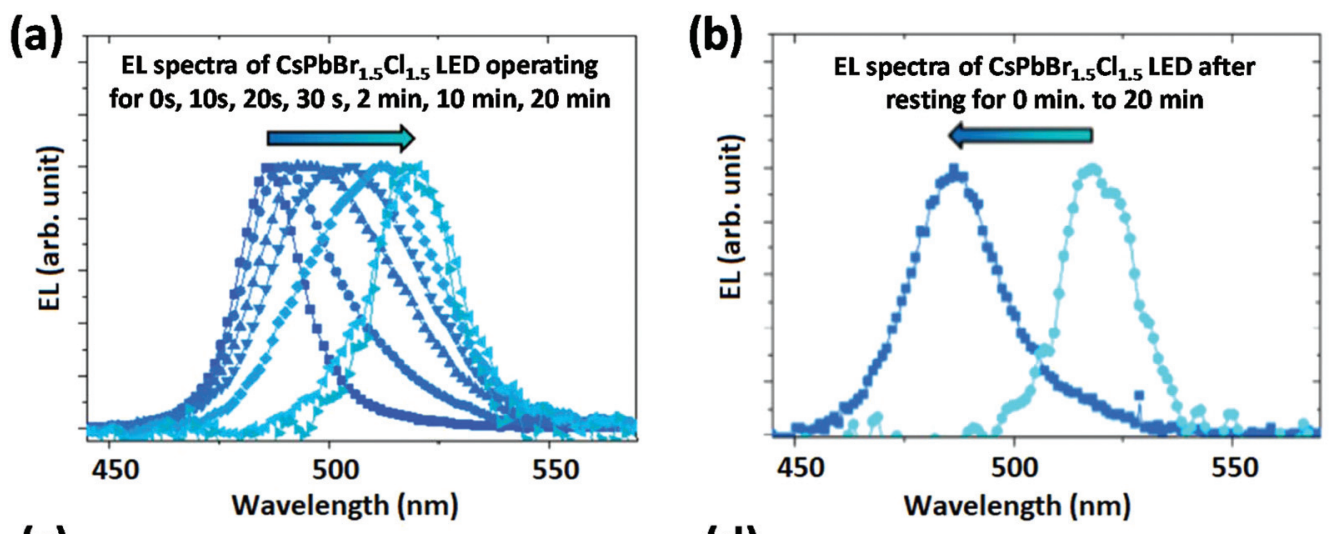

(c)

(d)
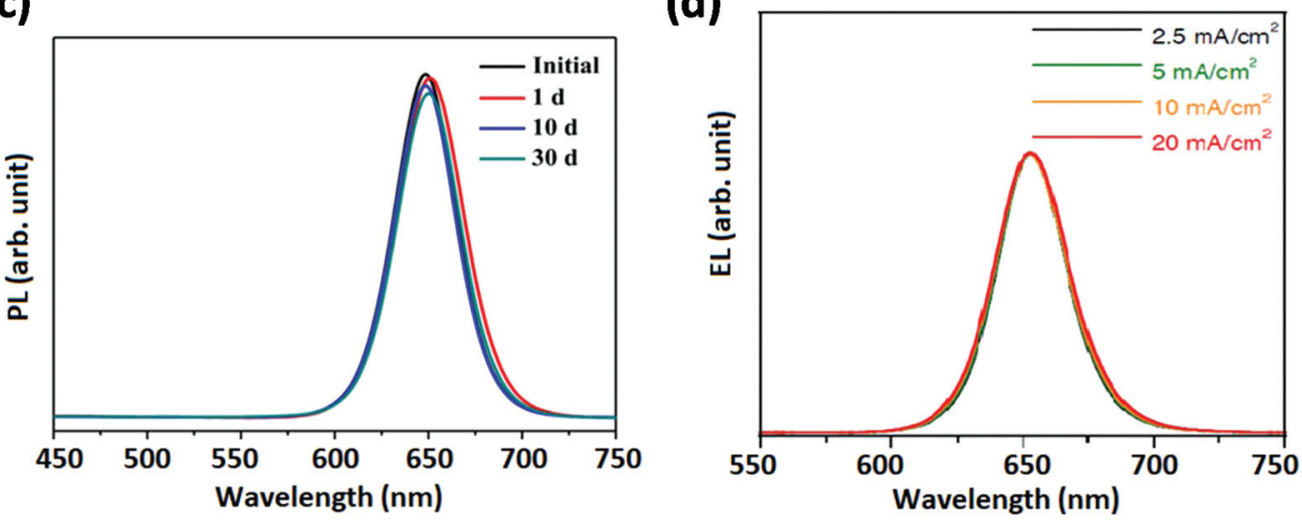

Fig. 6 Colour stability of blue PeLEDs. EL spectra recorded (a) after different time intervals and (b) after resting for 0/20 min. Reproduced with permission. ${ }^{17}$ Copyright $\odot 2016$, John Wiley and Sons. (c) PL spectra of $\mathrm{CsPb}\left(\mathrm{I}_{1-x} \mathrm{Br}_{x}\right)_{3} \mathrm{PNCs}$ with a metal stearate solid matrix. Reproduced with permission. ${ }^{59}$ Copyright $\odot 2018$, American Chemical Society. (d) EL spectra under various current densities. Reproduced with permission. ${ }^{14}$ Copyright $\odot$ 2018, Springer Nature. 
colour-stable red emission $(667 \mathrm{~nm})$ tuned from the near-infrared region $(790 \mathrm{~nm})$ by decreasing the crystal size of perovskite films. ${ }^{61}$

\subsection{Photoluminescence quantum efficiency}

The improvement of the PLQEs of blue emissive perovskite films is necessary for realizing highly efficient blue PeLEDs as the EQE of a PeLED is decisively determined by the PLQE of its emissive layer and light out-coupling efficiency. ${ }^{16,24}$ Wider bandgap materials have more sub-bandgap states and a high defect density as compared to smaller bandgap materials, ${ }^{62}$ raising difficulties for obtaining blue emissive perovskites with high PLQEs. In addition, self-quenching of PNCs during deposition into thin films from colloidal solutions, which is mainly due to the formation of surface defects, should be suppressed. ${ }^{63}$ A possible way to improve the PLQEs of blue emissive PNCs is the doping of metal ions such as $\mathrm{Mn}^{2+}$, which can passivate non-radiative recombination centers. ${ }^{64,65}$ A successful example was reported by Hou et al., where the PLQE of blue $\mathrm{CsPb}\left(\mathrm{Br}_{1-x} \mathrm{Cl}_{x}\right)_{3}$ PNCs was increased from $9 \%$ to $28 \%$ (Fig. 5a). ${ }^{57}$ Metal halides (e.g., $\mathrm{ZnX}_{2}$ ) can also help to suppress sub-bandgap states. ${ }^{45}$ Similar approaches can be used for improving the PLQEs of blue emissive perovskites. For 2D blue perovskites, the suppression of exciton-phonon coupling can largely increase the PLQE up to $79 \%$. ${ }^{66}$ Passivation of defects at grain boundaries and film surfaces can also increase the PLQEs of perovskite films. ${ }^{67}$ Morphology control by additives such as PEO (poly(ethylene oxide)) and crown ethers can largely promote the PLQEs of green emissive perovskites. ${ }^{68-70}$ These approaches could also be valid for blue perovskites.

\subsection{Device structure}

Blue emissive perovskites such as $\mathrm{CsPb}\left(\mathrm{Br}_{1-x} \mathrm{Cl}_{x}\right)_{3}$ have a deep valence band maximum ( $\approx 6.1 \mathrm{eV}$ ) (Fig. 7), ${ }^{54}$ which can lead to a large charge injection barrier for blue PeLEDs. Wide bandgap hole-transport layers (HTLs) with matching energy levels are needed to facilitate hole injection in blue PeLEDs. In addition, emission quenching at the interface between the HTL/ETL and the perovskite layer should be minimized. Gangishetty et al. found that the TFB/PFI layer shows less emission quenching than the NiO layer for $\operatorname{CsPb}\left(\mathrm{Br}_{1-x} \mathrm{Cl}_{x}\right)_{3} \cdot{ }^{54}$ Hence, the EQE was improved from $0.03 \%$ to $0.5 \%$ for blue PeLEDs (Fig. 4f). Similarly, Zhang et al. found that the insertion of a thin layer of PVP (poly(vinyl pyrrolidone)) between $\mathrm{ZnO}$ and the green emissive perovskite layer can realize an enhancement in PLQE, leading to an enhanced EQE from $0.09 \%$ to $2.41 \%$ for $\mathrm{CsPbBr}_{3}$ based green PeLEDs. ${ }^{71}$ Considering that blue emissive perovskites have wide bandgaps, similar approaches should be taken into consideration to suppress emission quenching by the HTL/ETLs with lower bandgaps or even sub-bandgap states. Some possible materials with energy levels are shown in Fig. 7. In addition, p-typedoped HTLs and n-type-doped ETLs can be used to reduce the charge injection barrier at the interface between the HTL/ETL and perovskite and tune the charge transport properties, ${ }^{72}$ and thus improve hole/electron injection and transport balance to realize high EQEs. For example, CBP (4,4-bis( $N$-carbazolyl)-1,1biphenyl) or PVK can be doped with $\mathrm{MoO}_{x}$ to improve hole injection in blue PeLEDs. In addition, a dipole functional interlayer such as PEI (polyethylenimine), PEIE, PFI etc., can be used to tune the work function of HTL/ETLs to get better charge injection. ${ }^{73-75}$

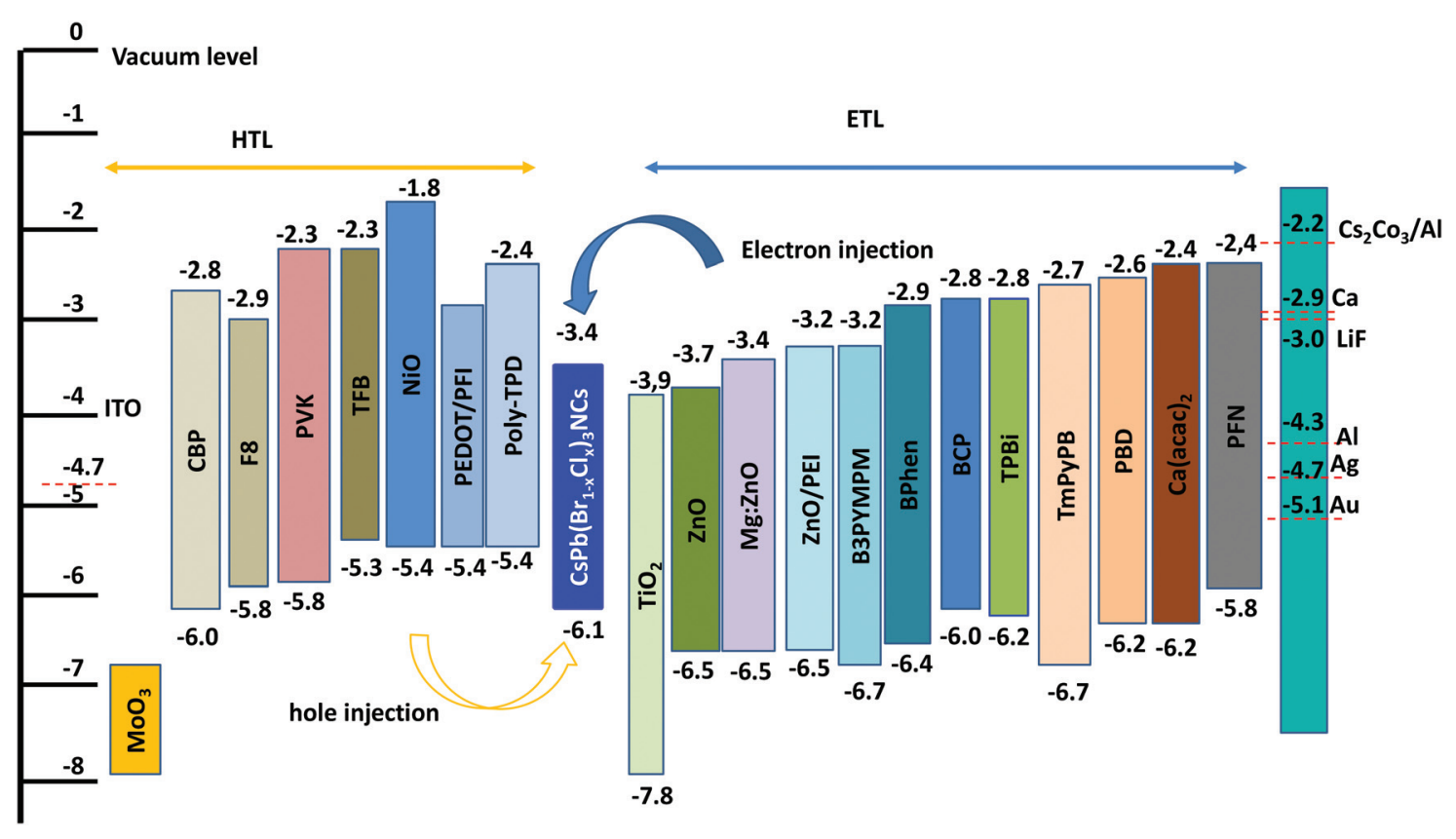

Fig. 7 Energy levels of various hole (HTL) and electron-transport layer (ETL) materials with blue emissive PNCs. 


\section{Conclusion and outlook}

We have summarized the current scenario of blue PeLEDs and discussed the challenges in terms of colour instability, poor PLQE, and device structure. Plausible strategies are provided to stabilize the colour stability and improve the PLQE of blue emissive perovskites. Lowering the dimensionality of pure bromide perovskites can be a very plausible way to realize efficient and colour-stable blue emissive perovskites. This can be performed in combination of defect passivation of perovskites using additives. In addition, emission quenching at the interfaces between the HTL/ETL and perovskite layer should be minimized. Wide bandgap HTL/ETLs with negligible subbandgap states are thus needed. Alternatively, a thin interlayer of insulators such as PFI and PVP can be used to avoid emission quenching by the HTL/ETLs. In addition to efficiency, the device operational lifetime is also a major concern for blue PeLEDs. It will be desirable for future displays and lighting applications to design PeLEDs with a high efficiency and excellent stability. We believe that this can be realized by elaborate design of new materials and device architectures.

\section{Conflicts of interest}

There are no conflicts to declare.

\section{Acknowledgements}

We would like to acknowledge the financial support from the ERC Starting Grant (717026) and the Swedish Research Council (2016-05855). X. K. L. is a Marie Skłodowska-Curie Fellow (798861).

\section{References}

1 L. Protesescu, S. Yakunin, M. I. Bodnarchuk, F. Krieg, R. Caputo, C. H. Hendon, R. X. Yang, A. Walsh and M. V. Kovalenko, Nano Lett., 2015, 15, 3692-3696.

2 (a) L. C. Schmidt, A. Pertegas, S. Gonzalez-Carrero, O. Malinkiewicz, S. Agouram, G. M. Espallargas, H. J. Bolink, R. E. Galian and J. Perez-Prieto, J. Am. Chem. Soc., 2014, 136, 850-853; (b) N. K. Kumawat, D. Gupta and D. Kabra, Energy Technol., 2017, 5, 1734-1749.

3 (a) A. Swarnkar, A. R. Marshall, E. M. Sanehira, B. D. Chernomordik, D. T. Moore, J. A. Christians, T. Chakrabarti and J. M. Luther, Science, 2016, 354, 92-95; (b) A. Kojima, K. Teshima, Y. Shirai and T. Miyasaka, J. Am. Chem. Soc., 2009, 131, 6050-6051; (c) M. Saliba, T. Matsui, J. Y. Seo, K. Domanski, J. P. Correa-Baena, M. K. Nazeeruddin, S. M. Zakeeruddin, W. Tress, A. Abate, A. Hagfeldt and M. Gratzel, Energy Environ. Sci., 2016, 9, 1989-1997.

4 (a) Y. Wang, X. Li, J. Song, L. Xiao, H. Zeng and H. Sun, Adv. Mater., 2015, 27, 7101-7108; (b) F. Deschler, M. Price,
S. Pathak, L. Klintberg, D. D. Jarausch, R. Higler, S. Huettner, T. Leijtens, S. D. Stranks, H. J. Snaith, M. Atature, R. T. Phillips and R. H. Friend, J. Phys. Chem. Lett., 2014, 5, 1421-1426.

5 (a) J. Song, J. Li, X. Li, L. Xu, Y. Dong and H. Zeng, Adv. Mater., 2015, 27, 7162-7167; (b) Q. V. Le, H. W. Jang and S. Y. Kim, Small Methods, 2018, 2, 1700419.

6 (a) P. Ramasamy, D. H. Lim, B. Kim, S. H. Lee, M. S. Lee and J. S. Lee, Chem. Commun., 2016, 52, 2067-2070; (b) C. Bao, J. Yang, S. Bai, W. Xu, Z. Yan, Q. Xu, J. Liu, W. Zhang and F. Gao, Adv. Mater., 2018, 30, 1803422.

7 Q. Chen, J. Wu, X. Ou, B. Huang, J. Almutlaq, A. A. Zhumekenov, X. Guan, S. Han, L. Liang, Z. Yi, J. Li, X. Xie, Y. Wang, Y. Li, D. Fan, D. B. L. Teh, A. H. All, O. F. Mohammed, O. M. Bakr, T. Wu, M. Bettinelli, H. Yang, W. Huang and X. Liu, Nature, 2018, 561, 8893.

8 K. Lin, J. Xing, L. N. Quan, F. P. Garcia de Arquer, X. Gong, J. Lu, L. Xie, W. Zhao, D. Zhang, C. Yan, W. Li, X. Liu, Y. Lu, J. Kirman, E. H. Sargent, Q. Xiong and Z. Wei, Nature, 2018, 562, 245-248.

9 Y.-H. Kim, H. Choa and T.-W. Lee, Proc. Natl. Acad. Sci. U. S. A., 2016, 113, 11694-11702.

10 Z.-K. Tan, R. S. Moghaddam, M. L. Lai, P. Docampo, R. Higler, D. Felix, M. Price, A. Sadhanala, L. M. Pazos, D. Credgington, F. Ha-nusch, T. Bein, H. J. Snaith and R. H. Friend, Nat. Nanotechnol., 2014, 9, 687692.

11 J. C. Yu, D. B. Kim, E. D. Jung, B. R. Lee and M. H. Song, Nanoscale, 2016, 8, 7036-7042.

12 H. Cho, S.-H. Jeong, M.-H. Park, Y.-H. Kim, C. Wolf, C.-L. Lee, J. H. Heo, A. Sadhanala, NoS. Myoung, S. Yoo, S. H. Im, R. H. Friend and T.-W. Lee, Science, 2015, 350, 1222-1225.

13 H. Wang, H. Yu, W. Xu, Z. Yuan, Z. Yan, C. Wang, X. Liu, M. Fahlman, J.-M. Liu, X.-K. Liu and F. Gao, J. Mater. Chem. C, 2018, 6, 6996-7002.

14 T. Chiba, Y. Hayashi, H. Ebe, K. Hoshi, J. Sato, S. Sato, Y.-J. Pu, S. Ohisa and J. Kido, Nat. Photonics, 2018, 12, 681687.

15 (a) Y. Cao, N. Wang, H. Tian, J. Guo, Y. Wei, H. Chen, Y. Miao, W. Zou, K. Pan, Y. He, H. Cao, Y. Ke, M. Xu, Y. Wang, M. Yang, K. Du, Z. Fu, D. Kong, D. Dai, Y. Jin, G. Li, H. Li, Q. Peng, J. Wang and W. Huang, Nature, 2018, 562, 249-253; (b) B. Zhao, S. Bai, V. Kim, R. Lamboll, R. Shivanna, F. Auras, J. M. Richter, L. Yang, L. Dai, M. Alsari, X.-J. She, L. Liang, J. Zhang, S. Lilliu, P. Gao, H. J. Snaith, J. Wang, N. C. Greenham, R. H. Friend and and D. Di, Nat. Photonics, 2018, 12, 783-789.

16 X.-B. Shi, Y. Liu, Z. Yuan, X.-K. Liu, Y. Miao, J. Wang, S. Lenk, S. Reineke and F. Gao, Adv. Opt. Mater., 2018, 6, 1800667.

17 G. Li, F. W. R. Rivarola, N. J. L. K. Davis, S. Bai, T. C. Jellicoe, F. de la Pena, S. Hou, C. Ducati, F. Gao, R. H. Friend, N. C. Greenham and Z.-K. Tan, Adv. Mater., 2016, 28, 3528-3534. 
18 N. K. Kumawat, A. Dey, A. Kumar, S. P. Gopinathan, K. L. Narasimhan and D. Kabra, ACS Appl. Mater. Interfaces, 2015, 7, 13119-11312.

19 N. K. Kumawat, N. Jain, A. Dey, K. L. Narasimhan and D. Kabra, Adv. Funct. Mater., 2017, 27, 1603219.

20 N. K. Kumawat, A. Dey, K. L. Narasimhan and D. Kabra, ACS Photonics, 2015, 2, 349-354.

21 A. Sadhanala, S. Ahmad, B. Zhao, N. Giesbrecht, P. M. Pearce, F. Deschler, R. L. Z. Hoye, K. C. Godel, T. Bein, P. Docampo, S. E. Dutton, M. F. L. De Volder and R. H. Friend, Nano Lett., 2015, 15, 6095-6101.

22 H. P. Kim, J. Kim, B. S. Kim, H.-M. Kim, J. Kim, A. Rashid bin Mohd Yusoff, J. Jang and M. K. Nazeeruddin, Adv. Opt. Mater., 2017, 5, 1600920.

23 A. F. Gualdron-Reyes, S. J. Yoon and I. Mora-Sero, Curr. Opin. Electrochem., 2018, 11, 84-90.

24 X.-K. Liu and F. Gao, J. Phys. Chem. Lett., 2018, 9, 22512258.

25 D. Liang, Y. Peng, Y. Fu, M. J. Shearer, J. Zhang, J. Zhai, Y. Zhang, R. J. Hamers, T. L. Andrew and S. Jin, ACS Nano, 2016, 10, 6897-6904.

26 L. Cheng, Y. Cao, R. Ge, Y.-Q. Wei, N.-N. Wanga, J.-P. Wang and W. Huang, Chin. Chem. Lett., 2017, 28, 29-31.

27 L. Ni, U. Huynh, A. Cheminal, T. H. Thomas, R. Shivanna, T. F. Hinrichsen, S. Ahmad, A. Sadhanala and A. Rao, ACS Nano, 2017, 11, 10834-10843.

28 M. Yuan, L. N. Quan, R. Comin, G. Walters, R. Sabatini, O. Voznyy, S. Hoogland, Y. Zhao, E. M. Beauregard, P. Kanjanaboos, Z. Lu, D. H. Kim and E. H. Sargent, Nat. Nanotechnol., 2016, 9, 872-877.

29 Z. Yuan, Y. Shu, Y. Xin and B. Ma, Chem. Commun., 2016, 52, 3887-3890.

30 N. Wang, L. Cheng, R. Ge, S. Zhang, Y. Miao, W. Zou, C. Yi, Y. Sun, Y. Cao, R. Yang, Y. Wei, Q. Guo, Y. Ke, M. Yu, Y. Jin, Y. Liu, Q. Ding, D. Di, L. Yang, G. Xing, H. Tian, C. Jin, F. Gao, R. H. Friend, J. Wang and W. Huang, Nat. Photonics, 2016, 10, 699-704.

31 X. Yang, X. Zhang, J. Deng, Z. Chu, Q. Jiang, J. Meng, P. Wang, L. Zhang, Z. Yin and J. You, Nat. Commun., 2018, 9, 570 .

32 J. Qing, X.-K. Liu, M. Li, F. Liu, Z. Yuan, E. Tiukalova, Z. Yan, M. Duchamp, S. Chen, Y. Wang, S. Bai, J.-M. Liu, H. J. Snaith, C.-S. Lee, T. C. Sum and F. Gao, Adv. Energy Mater., 2018, 8, 1800185.

33 C. Lan, Z. Zhou, R. Wei and J. C. Ho, Mater. Today Energy, 2019, 11, 61-82.

34 S. Kumar, J. Jagielski, S. Yakunin, P. Rice, Y.-C. Chiu, M. Wang, G. Nedelcu, Y. Kim, S. Lin, E. J. G. Santos, M. V. Kovalenko and C.-J. Shih, ACS Nano, 2016, 10, 97209729.

35 Z. Chen, C. Zhang, X.-F. Jiang, M. Liu, R. Xia, T. Shi, D. Chen, Q. Xue, Y.-J. Zhao, S. Su, H.-L. Yip and Y. Cao, Adv. Mater., 2017, 29, 1603157.

36 D. N. Congreve, M. C. Weidman, M. Seitz, W. Partimongkol, N. S. Dahod and W. A. Tisdale, ACS Photonics, 2017, 4, 476-481.
37 Q. Wang, J. Ren, X.-F. Peng, X.-X. Ji and X.-H. Yang, ACS Appl. Mater. Interfaces, 2017, 9, 29901-29906.

38 P. Vashishtha, M. Ng, S. B. Shivarudraiah and J. E. Halpert, Chem. Mater., 2019, 31, 83-89.

39 J. Xing, Y. Zhao, M. Askerka, L. N. Quan, X. Gong, W. Zhao, J. Zhao, H. Tan, G. Long, L. Gao, Z. Yang, O. Voznyy, J. Tang, Z.-H. Lu, Q. Xiong and E. H. Sargent, Nat. Commun., 2018, 9, 3541.

40 Y. Yuan, Z. Liu, Z. Liu, L. Peng, Y. Li and A. Tang, Appl. Surf. Sci., 2017, 405, 280-288.

41 (a) A. Pan, B. He, X. Fan, Z. Liu, J. J. Urban, A. P. Alivisatos, L. He and Y. Liu, ACS Nano, 2016, 8, 7943-7654; (b) A. Dey, P. Rathod and D. Kabra, Adv. Opt. Mater., 2018, 6, 1800109.

42 Q. Sun, C. Ni, Y. Yu, S. Attique, S. Wei, Z. Ci, J. Wang and S. Yang, J. Mater. Chem. C, 2018, 6, 12484-12492.

43 M. V. Kovalenko, L. Protesescu and M. I. Bodnarchuk, Science, 2017, 358, 745-750.

44 F. Zhang, H. Zhong, C. Chen, X. G. Wu, X. Hu, H. Huang, J. Han, B. Zou and Y. Dong, ACS Nano, 2015, 9, 4533-4542.

45 (a) J. Song, T. Fang, J. Li, L. Xu, F. Zhang, B. Han, Q. Shan and H. Zeng, Adv. Mater., 2018, 1805409; (b) N. K. Kumawat, A. Swarnkar, A. Nag and D. Kabra, J. Phys. Chem. C, 2018, 122, 13767-13773.

46 S. Sun, D. Yuan, Y. Xu, A. Wang and Z. Deng, ACS Nano, 2016, 10, 3648-3657.

47 A. Pan, B. He, X. Fan, Z. Liu, J. J. Urban, A. P. Alivisatos, L. He and Y. Liu, ACS Nano, 2016, 10, 7943-7954.

48 E. Yassitepe, Z. Yang, O. Voznyy, Y. Kim, G. Walters, J. A. Castaneda, P. Kanjanaboos, M. Yuan, X. Gong, F. Fan, J. Pan, S. Hoogland, R. Comin, O. M. Bakr, L. A. Padilha, A. F. Nogueira and E. H. Sargent, Adv. Funct. Mater., 2016, 26, 8757-8763.

49 H. Huang, B. Chen, Z. Wang, T. F. Hung, A. S. Susha, H. Zhongb and A. L. Rogach, Chem. Sci., 2016, 7, 56995703.

50 B. Luo, Y.-C. Pu, S. A. Lindley, Y. Yang, L. Lu, Y. Li, X. Li and J. Z. Zhang, Angew. Chem., Int. Ed., 2016, 55, 8864.

51 L. Z. Wu, Q. X. Zhong, D. Yang, M. Chen, H. C. Hu, Q. Pan, H. Y. Liu, M. H. Cao, Y. Xu, B. Q. Sun and Q. Zhang, Langmuir, 2017, 33, 12689.

52 J. Pan, L. N. Quan, Y. Zhao, W. Peng, B. Murali, S. P. Sarmah, M. Yuan, L. Sinatra, N. M. Alyami, J. Liu, E. Yassitepe, Z. Yang, O. Voznyy, R. Comin, M. N. Hedhili, O. F. Mohammed, Z. H. Lu, D. H. Kim, E. H. Sargent and O. M. Bakr, Adv. Mater., 2016, 28, 8718-8725.

53 J. Xing, F. Yan, Y. Zhao, S. Chen, H. Yu, Q. Zhang, R. Zeng, H. V. Demir, X. Sun, A. Huan and Q. Xiong, ACS Nano, 2016, 10, 6623-6630.

54 M. K. Gangishetty, S. Hou, Q. Quan and D. N. Congreve, Adv. Mater., 2018, 30, 1706226.

55 I. L. Braly, R. J. Stoddard, A. Rajagopal, A. R. Uhl, J. K. Katahara, A. K.-Y. Jen and H. W. Hillhouse, ACS Energy Lett., 2017, 2, 1841-1847.

56 X. Tang, M. van den Berg, E. Gu, A. Horneber, G. J. Matt, A. Osvet, A. J. Meixner, D. Zhang and C. J. Brabec, Nano Lett., 2018, 18, 2172-2178. 
57 S. Hou, M. K. Gangishetty, Q. Quan and D. N. Congreve, Joule, 2018, 2, 2421-2433.

58 A. K. Guria, S. K. Dutta, S. D. Adhikari and N. Pradhan, ACS Energy Lett., 2017, 2, 1014-1021.

59 Y. Chang, Y. J. Yoon, G. Li, E. Xu, S. Yu, C.-H. Lu, Z. Wang, Y. He, C. H. Lin, B. K. Wagner, V. V. Tsukruk, Z. Kang, N. Thadhani, Y. Jiang and Z. Lin, ACS Appl. Mater. Interfaces, 2018, 10, 37267-37276.

60 K. Hoshi, T. Chiba, J. Sato, Y. Hayashi, Y. Takahashi, H. Ebe, S. Ohisa and J. Kido, ACS Appl. Mater. Interfaces, 2018, 10, 24607-24612.

61 H. Yu, H. Wang, J. Zhang, J. Lu, Z. Yuan, W. Xu, L. Hultman, A. A. Bakulin, R. H. Friend, J. Wang, X.-K. Liu and F. Gao, Small, 2019, DOI: 10.1002/smll.201804947.

62 C. M. Sutter-Fella, D. W. Miller, Q. P. Ngo, E. T. Roe, F. M. Toma, I. D. Sharp, M. C. Lonergan and A. Javey, ACS Energy Lett., 2017, 2, 709-715.

63 A. Kirakosyan, S. Yun, S.-G. Yoon and J. Choi, Nanoscale, 2018, 10, 1885-1891.

64 D. Parobek, B. J. Roman, Y. Dong, H. Jin, E. Lee, M. Sheldon and D. H. Son, Nano Lett., 2016, 16, 7376-7380. 65 X. Li, Y. Guo and B. Luo, Crystals, 2018, 8, 4.

66 X. Gong, O. Voznyy, A. Jain, W. Liu, R. Sabatini, Z. Piontkowski, G. Walters, G. Bappi, S. Nokhrin, O. Bushuyev, M. Yuan, R. Comin, D. McCamant, S. O. Kelley and E. H. Sargent, Nat. Mater., 2018, 17, 550-556.
67 F. Wang, S. Bai, W. Tress, A. Hagfeldt and F. Gao, npj Flex. Electron., 2018, 2, 22.

68 B. Jeong, H. Han, Y. J. Choi, S. H. Cho, E. H. Kim, S. W. Lee, J. S. Kim, C. Park, D. Kim and C. Park, Adv. Funct. Mater., 2018, 28, 1706401.

69 S. A. Veldhuis, Y. F. Ng, R. Ahmad, A. Bruno, N. F. Jamaludin, B. Damodaran, N. Mathews and S. G. Mhaisalkar, ACS Energy Lett., 2018, 3, 526-531.

70 M. Ban, Y. Zou, J. P. H. Rivett, Y. Yang, T. H. Thomas, Y. Tan, T. Song, X. Gao, D. Credington, F. Deschler, H. Sirringhaus and B. Sun, Nat. Commun., 2018, 9, 3892.

71 L. Zhang, X. Yang, Q. Jiang, P. Wang, Z. Yin, X. Zhang, H. Tan, Y. Yang, M. Wei, B. R. Sutherland, E. H. Sargent and J. You, Nat. Commun., 2017, 8, 15640.

72 M. Kuhn, E. Mankel, A. Kohn, T. Mayer and W. Jaegermann, Phys. Status Solidi B, 2016, 253, 1697-1706.

73 Y.-H. Kim, H. Cho, J. H. Heo, T.-S. Kim, N. S. Myoung, C.-L. Lee, S. H. Im and T.-W. Lee, Adv. Mater., 2015, 27, 1248-1254.

74 R. L. Z. Hoye, M. R. Chua, K. P. Musselman, G. Li, M.-L. Lai, Z.-K. Tan, N. C. Greenham, J. L. MacManusDriscoll, R. H. Friend and D. Credgington, Adv. Mater., 2015, 27, 1414-1419.

75 B. R. Lee, E. D. Jung, J. S. Park, Y. S. Nam, S. H. Min, B.-S. Kim, K.-M. Lee, J.-R. Jeong, R. H. Friend, J.-S. Kim, S. O. Kim and M. H. Song, Nat. Commun., 2014, 5, 4840. 